ence, is expected to be welcomed by the Clinton administration, as is NSF's current review of its mission and Massey's determination that the foundation should serve industry as well as academics.

At the same time, the two directors have very different personal styles. Healy's brashness has alienated many Democratic legislators, and there are few who would defend her if the Clinton administration decided that she is a political liability. In contrast, Massey has such a nonconfrontational style that he is unlikely to cause any problems for a president with more pressing issues on his agenda.

The future of funding for basic research is no easier to predict. Last year, in a break with tradition, Congress did not even match the president's request for $\mathrm{NIH}$, and there are those who blame Healy for not fighting harder. As for NSF, the president's annual request for a double-digit increase once again was virtualiy ignored by a Congress that needed more money for veterans' health care, housing, the space station and other programmes that come out of the same appropriations bill.

President Bush is roundly criticized by researchers for proposing large increases for science but being indifferent to their fate. However, Republicans could always place the blame on a Congress controlled by the Democrats. Clinton will not have that option, of course, and it is expected that he will propose smaller increases but fight harder to achieve them.

Jeffrey Mervis

\title{
Fraunhofer institutes told to get more from industry
}

Munich. The Fraunhofer Society, which runs 47 applied research institutes in Germany, has been warned that it must look more to industry for its financing. The German Ministry of Research and Technology said last week that it will reduce its contribution to the society and suggested that the society should consolidate rather than continue to expand.

The Fraunhofer Society was founded in 1949 by industry and government as a nonprofit-making body to bridge the gap between academic institutions and industry. Its success in 'technology transfer' has been the envy of many governments, particularly Britain's, which is investigating the possibility of setting up similar systems (see Nature 355, 757; 1992). The number of institutes it runs has nearly doubled in the past 20 years.

The society receives its basic support from public funds, and additional money from various companies. Research minister Heinz Riesenhuber says that the society should increase the fraction of its income from contract research from 35 per cent to at least 40 per cent. Although the federal government will be making fewer grants, it will retain the
90:10 split between federal and local governments.

State funding of the institutes reached a peak this year of DM343 million (US\$220 million), including the establishment of eight institutes in the former East Germany. The government's Ministry of Research and Technology, whose own budget has been reduced, says that Fraunhofer institutes will bear a larger proportion of the cuts than other institutes conducting basic research but that plans for development of the eight new institutes will go forward.

Germany's economy is driven by small and medium-size companies that find it cost-effective to contract out their research. But the Fraunhofer Society believes that the recession will make it harder for its institutes to make up the shortfall created by government, and that some of its 7,600 employees may have to be laid off. Those companies can also look to research being done in the United States or Japan, warns the society's president, Max Syrbe, if the German government does not maintain the excellence of its applied institutes.

Alison Abbott

\section{Pulsars to star in forthcoming UK music festival}

London. The Lovell radiotelescope at Britain's Nuffield Radio Astronomy Laboratories at Jodrell Bank will share top billing in a concert this month. The occasion is a performance of "Le Noirde l'Etoile" (The Dark Side of the Star) by the French composer Gerard Grisey at the Huddersfield Contemporary Music Festival.

The multimedia work incorporates text by French astronomer Jean-Pierre Luminet, an intricate light show projected onto an acoustic canopy that envelops performers and audience, music played by the six members of Les Percussions de Strasbourg and the sounds of two pulsars. One pulsar, in the Vela nebula in the southern skies, is prerecorded while the second, designated PSR0329-54, will be relayed by Jodrell Bank direct to the Huddersfield Sports Centre. The concert will take place on 22 November.

At two points in the performance the six musicians will fall silent, leaving the way clear for the pulsar sounds to be conveyed

over a battery of loudspeakers. Elsewhere, the radio pulsations are heard only by the musicians and provide the basic tempo for the work.

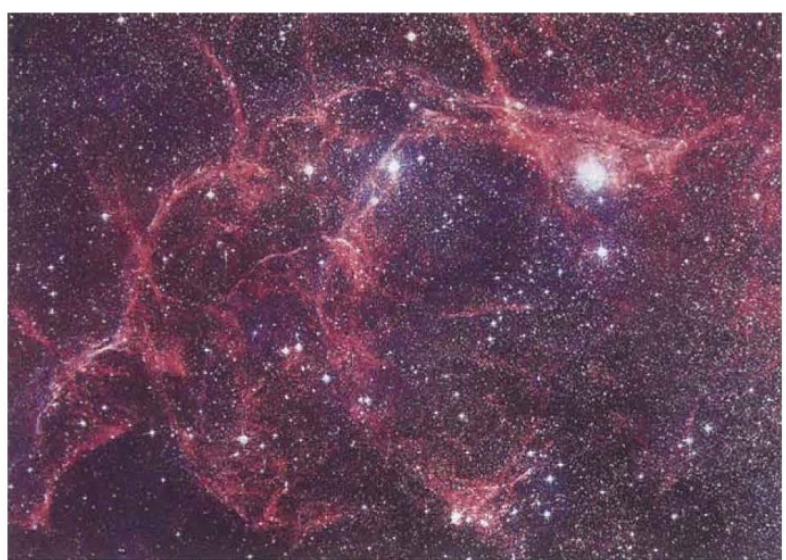

The Vela nebula: a source of sound

Grisey was introduced to pulsar sounds in 1985 by cosmologist Joseph Silk while teaching composition at the University of California at Berkeley. He likens the sound to African drums and says he was inspired by the varying tone colour of the pulses (from the stochastic processes that generate the radio signals) and the regularity of the rhythm.

The work has been performed at Brussels and Strasbourg using live sounds transmitted by the radiotelescope at Nancy. But the superior sensitivity of the Lovell telescope and the technical lessons learnt from those performances is expected to make for a truer rendition of the artist's intentions.

The cultural excursion will not interfere with the telescope's scientific programme, according to Andrew Lyne of Jodrell Bank. Radioastronomers routinely turn the telescope dish towards various pulsars to check their timing and to look for changes in the interstellar medium traversed by the radio signals; the concert is simply a matter of squaring this particular pointing with the performance.

Roland Pease 